OPEN ACCESS

Edited by: Andrew James Jonathan

Maclntosh,

Kyoto University, Japan

Reviewed by:

Martin Kavaliers,

Western University, Canada

Ajai Vyas,

Nanyang Technological University,

Singapore

${ }^{*}$ Correspondence:

Heike Lutermann

hlutermann@zoology.up.ac.za

Specialty section:

This article was submitted to Behavioral and Evolutionary Ecology,

a section of the journal

Frontiers in Ecology and Evolution

Received: 17 December 2021

Accepted: 10 February 2022

Published: 03 March 2022

Citation:

Lutermann $\mathrm{H}$, Butler KB and Bennett NC (2022) Parasite-Mediated Mate Preferences in a Cooperatively Breeding Rodent.

Front. Ecol. Evol. 10:838076. doi: $10.3389 /$ fevo.2022.838076

\section{Parasite-Mediated Mate Preferences in a Cooperatively Breeding Rodent}

\author{
Heike Lutermann*, Kemba B. Butler and Nigel C. Bennett \\ Department of Zoology and Entomology, Mammal Research Institute, University of Pretoria, Pretoria, South Africa
}

Females of many species discriminate among males when choosing a mate and this can bear indirect and direct benefits including the avoidance of parasite transmission from infested males. In rodents, this may be mediated by androgen hormones that affect the expression of urinary odors. Female choosiness may also vary with a female's infestation status, with infested females being less choosy. In the current study we tested the preference of cooperatively breeding highveld mole-rat (Cryptomys hottentotus hottentotus) females for male urinary odors from healthy males and those naturally infested with a cestode (Mathevotaenia sp.). Thirty females (15 healthy, 15 infested) were allowed to explore a Y-maze with urine samples from healthy and infested males and the frequency of entering choice arms and chambers as well as the duration spend with each odor sample was recorded. Infestation status did neither affect male body mass, urinary testosterone, nor cortisol levels or the body condition of females. Although overall female activity was not affected by infestation status, infested females entered choice arms and chambers significantly less frequently than healthy females. Surprisingly, healthy females preferred odors from infested males while the opposite was true for infested females, independent of male hormone levels. As the study species lives in groups that tend to share the same infestation status, we suggest that highveld mole-rat females may exhibit a preference for unfamiliar odors, possibly as an indicator of genetic diversity, rather than discriminate between infestation status of males. Similar mechanisms may also play a role in other social species.

Keywords: Bathyergidae, mate choice, sociality, parasite, Mathevotaenia, androgen

\section{INTRODUCTION}

In many species, females actively discriminate between potential mates (Andersson, 1994). Such mate choice decisions can have both indirect and direct benefits for choosing females (Jennions and Petrie, 1997; Kokko et al., 2003). The former include the transmission of genes that increase offspring fitness by increasing their fecundity, survival and/or mating success (Jennions and Petrie, 1997). Direct benefits can include the acquisition of nutritional benefits through nuptial gifts or paternal care, but also preventing parasite transmission by avoiding infested males (Able, 1996).

Female mate choice is often based on elaborate secondary sexual traits as the costs of such traits can only be sustained by high-quality males (i.e., those in good condition and/or without parasites) (Hamilton and Zuk, 1982; Folstad and Karter, 1992). While in many bird, fish and reptile species females may glean information about a male's infestation status from visual signals such as their nuptial coloration and courtship displays, olfactory cues from various glands, feces and 
urine replace these in mammalian species (Penn and Potts, 1998). Olfactory signals can provide information about attributes such as sex, reproductive status, individuality as well as body condition and constitute the most important source of social information in rodents (Johnston, 2003; Ferkin, 2018).

Rodent urine contains a variety of volatile and non-volatile compounds that are under androgen control (Kavaliers et al., 2005). Infection-related changes in condition (e.g., body mass) and endocrine status (e.g., testosterone and/or cortisol) (Willis and Poulin, 2000; Zala et al., 2004; Litvinova et al., 2005) can affect the quality and quantity of these volatiles, providing information to potential mates (Kavaliers et al., 2005; Kavaliers and Choleris, 2018). A number of studies in rodents have reported that females avoid odors of males infested with viruses, bacteria, arthropods or helminth (reviewed in Beltran-Bech and Richard, 2014).

Female preference for healthy males is not always apparent, however, and can be modified by a variety of factors including the costs of being choosy, a female's condition as well as social cues or the mating system (Poulin and Vickery, 1996; Jennions and Petrie, 1997; Klein et al., 1999; Buchholz, 2004; BeltranBech and Richard, 2014; Kavaliers and Choleris, 2018). In nature, female mate choice may entail energetic costs of traveling to sample several males, but also to the related increased exposure to predators and/or environmentally transmitted pathogens and parasites (Milinski and Bakker, 1992; Jennions and Petrie, 1997; Kokko et al., 2003). Thus, encounter probability rather than infestation status of males may determine female mate choice. However, even under benign laboratory conditions females may exhibit a lack discrimination or even a preference for infested males (Penn et al., 1998; Klein et al., 1999; Moshkin et al., 2002; Gourbal and Gabrion, 2004; Mazzi, 2004; Barthélémy et al., 2005; Dass et al., 2011; Lai et al., 2016). This could be a result of social cues from other individuals and experiments in laboratory mice (Mus musculus) have shown that exposure to odor cues from parasitized males prior to mate choice can reduce the avoidance behavior of healthy females (Kavaliers et al., 2003). Alternatively, the concomitant presence of female odors can increase the attractiveness of odors of infested males (Kavaliers et al., 2006).

As parasites obtain access to resources at the expense of their host (Poulin, 2007), infested females may be constrained in their ability to express mate choice (Poulin and Vickery, 1996). Only a limited number of studies have addressed this hypothesis (Beltran-Bech and Richard, 2014). Some that have tested this hypothesis report a lack of discrimination between healthy and infested males by infested females (Poulin, 1994; López, 1999; Mazzi, 2004; Aguilar et al., 2008) while others found a preference for infested males (Pfennig and Tinsley, 2002). Several of the former studies noted lower condition and/or activity levels of infested females suggesting energetic constraints on mate choice for these females (e.g., Poulin, 1994; López, 1999). Alternatively, the sensory capabilities of infested females may be impaired (Poulin and Vickery, 1996; Klein, 2003).

The majority of studies into parasite-mediated female mate choice in rodents have been conducted on classic laboratory animals, particularly mice (Beltran-Bech and Richard, 2014). However, the use of olfactory cues as an information source concerning parasitic infection status in wild rodents is not well understood. Here, we investigated the scent preferences of highveld mole-rats (Cryptomys hottentotus pretoriae) a member of the African rodent family Bathyergidae. This subterranean species is restricted to the summer-rainfall highveld regions of South Africa (Bennett and Faulkes, 2000). Highveld molerats are cooperative breeders that live in colonies of up to 12 individuals (Bennett and Faulkes, 2000). Non-breeding males are prevented from breeding due to incest avoidance but are physiologically indistinguishable from breeders (van Rensburg et al., 2003). Female highveld mole-rats are reflex ovulators that require the tactile stimulation of copulation to induce ovulation and non-breeding females are physiologically suppressed within their natal colonies (Malherbe et al., 2004). Nevertheless, nonbreeding females of several mole-rat species, including highveld mole-rats, readily engage in sexual activity with unfamiliar and/or unrelated males (Bennett et al., 1996, 1997, 2000; Clarke and Faulkes, 1999; Greeff and Bennett, 2000; Clarke et al., 2001; Bappert et al., 2012, Butler and Bennett, personal observation). This is likely an adaptation to the low encounter probability with unrelated males due to high energetic and survival costs of breeding dispersal in these rodents (Jarvis et al., 1994; Hazell et al., 2000). The ability of females to discriminate relatedness based on urinary cues has been investigated for several molerat species (Clarke and Faulkes, 1999; Bappert et al., 2012), but to date no study has addressed whether female molerats can discriminate between healthy and infested males and exhibit a preference for the former. Hence, the aim of this study was to assess how parasite infestation affects female odor preference and the mechanisms by which this may be mediated. We investigated whether wild-caught female highveld mole-rats displayed a preference for urinary cues from naturally healthy compared to infested males. Furthermore, we evaluated whether such preferences were linked to male body condition (using body mass as proxy) and/or urinary hormone (i.e., testosterone and cortisol) levels. We also assessed the effects of parasitism on the ability of a female to distinguish between odors. Highveld molerats of our study population are parasitized by three helminth species with cestodes (Mathevotaenia sp.) being the predominant endoparasites (Viljoen et al., 2011). Hence, we used naturally infested individuals in our study that represent conditions of a chronic infestation. We predicted that (1) females would be able to distinguish between males of different infestation status and that (2) healthy females would exhibit a preference for odor cues from healthy males while (3) infested females would have an impaired ability to discriminate (e.g., lower activity levels) and not exhibit strong preferences for olfactory cues from either infested or healthy male. Previous studies have shown that chronic infestation with Mathevotaenia sp. results in reduced urinary testosterone levels in male highveld mole-rats, while it did not affect urinary cortisol levels (Lutermann et al., 2012). Consequently, we hypothesized that (4) such preferences would be linked to urinary hormone levels and females would prefer urinary cues from males with high testosterone, but lower cortisol levels. 


\section{MATERIALS AND METHODS}

\section{Animal Capture and Maintenance}

Mole-rats were collected from areas in the suburbs of Pretoria in Gauteng Province, South Africa $\left(25^{\circ} 45^{\prime} \mathrm{S}, 28^{\circ} 10^{\prime} \mathrm{E}\right)$ from October 2008 through to September 2009. Individuals were captured using modified Hickman live traps (Hickman, 1979) baited with sweet potato and checked twice daily. All captured animals were weighed to the nearest $0.1 \mathrm{~g}$ (Scout Pro SPU123, Ohaus Corporation, United States) and sexed. Captured animals were housed in their colonies in plastic containers $(100 \times$ $75 \times 50 \mathrm{~cm}$ ) in a temperature-controlled room at $25 \pm 1^{\circ} \mathrm{C}$ and under a 12L: 12D lighting regime. Colonies are generally comprised of one breeding female (readily identified by her enlarged teats and perforated vagina), one, sometimes more, breeding males and their non-breeding offspring. Colony sizes ranged from three to seven individuals. Wood shavings were used as bedding and sweet potato, carrots and apple were available on an ad libitum basis. In our study population, two nematode species have been recorded at low prevalence (both: 4.4\%) and mean abundance (Protospirura sp.: 0.08, Heligmonina sp.: 0.06 ) compared to Mathevotaenia (prevalence: $71.9 \%$, abundance: 8.04) with the latter also likely to be more damaging due to their substantially larger size (Viljoen et al., 2011). Cestodes require an intermediate host, usually an arthropod, and cannot directly be transmitted. The intermediate host and life-cycle for Mathevotaenia sp. is unknown and hence, we could not employ artificial infestation of our study animals. The infestations of wild-caught individuals were identified based on shedding in feces represent chronic infestations. In contrast to acute infestations, hosts with chronic infestations have likely made physiological adjustments to restore homeostasis and minimize the costs of parasitism (Lutermann et al., 2012).

\section{Determination of Infection Status and Urine Collection}

For the determination of the infestation status and urine collection (see below), animals were removed from their colonies and placed individually in a spherical plastic container (height: $20 \mathrm{~cm}$; radius: $9.6 \mathrm{~cm}$ ) with a wire mesh base and a plastic collection tray placed underneath. Droppings deposited on the wire mesh base of these chambers were examined for the presence of proglottids. This method has been shown to allow a high accuracy in the identification of Mathevotaenia sp. infestation (Viljoen et al., 2011). To further ensure that individuals classified as healthy were indeed free of cestodes they were injected subcutaneously with $2 \mu \mathrm{l} / \mathrm{g}$ body mass Ivermectin (Noromectin ${ }^{\circledR}$, Norbrook Laboratories, Centurion, South Africa) while infested individuals received an injection of saline solution. We allowed a 2 -week period to elapse before the infestation status was confirmed by an additional examination of feces. Once their infestation status was confirmed urine was collected from 30 males (15 healthy, 15 infested). We provided apples as a source for energy and moisture during urine collection. Traps were checked at hourly intervals and any urine deposited in these trays was collected using pipettes, transferred to Eppendorf tubes and stored at $-20^{\circ} \mathrm{C}$ until used in the experiments.

\section{Odor Preference Tests}

The odor preferences of 15 healthy and 15 infested non-breeding female mole-rats were determined in a clear Perspex Y-maze. The maze consisted of 3 squares boxes $(20 \times 20 \times 20 \mathrm{~cm}$, one start chamber and two choice chambers) connected with Perspex tubing $(7.4 \mathrm{~cm}$ diameter). The start box, with a removable door, was connected to a $20 \mathrm{~cm}$ long tube, which in turn branched into two $50 \mathrm{~cm}$ long tubes (choice arms). Both tubes terminated in a choice chamber. Each choice chamber contained a urine sample $(1 \mathrm{ml})$ from either a healthy or infested male applied to $20 \mathrm{~g}$ of fresh sawdust.

Only non-breeding females were used and the odors presented to them originated from males that were unfamiliar to them and each female was tested only once. The identity of males providing urine samples was changed for each trial to reduce the risk of individual factors other than parasite load having an effect on odor preference. We alternated between the left and right choice chamber for the infested odor stimulus, to minimize potential side biases. Due to the substantial effort required to capture a sufficient number of infested, unfamiliar individuals, we used urine from each male twice, once for the non-infested and once for the infested females, and retained the same combinations.

All females were separated from their colonies for $6 \mathrm{~h}$ prior to the onset of a preference test to allow for habituation to isolation. We transferred females to the start chamber and allowed them to acclimatize for $15 \mathrm{~min}$. Once this time elapsed, we placed urine samples in the choice chambers and opened the start chamber, giving the female access to the maze. Females had unrestricted olfactory and physical contact with the odor samples during trials. We observed female behavior for $20 \mathrm{~min}$ and recorded the following variables: (1) Initial choice arm entered; (2) time spent in each arm and chamber; (3) number of times an arm or chamber was entered; and (4) time spent being active (i.e., not motionless for more than $5 \mathrm{~s}$ ). Between tests, we cleaned the Y-maze thoroughly with soapy water and $70 \%$ ethanol.

\section{Hormone Assays}

We determined the creatinine concentrations of all urine samples prior to the hormone analyses to correct for urine dilution (Bonney et al., 1982). Since creatinine is a breakdown product of tissue proteins, it is assumed to be released at a constant rate. This provides a means to standardize samples of different dilutions. We dispensed duplicate aliquots $(7 \mu \mathrm{l})$ of urine or standards into wells in a microplate together with $210 \mu \mathrm{l}$ freshly prepared alkaline picric reagent (1 volume alkaline triton solution: 1 volume saturated picric acid: 10 volumes deionized distilled water). The microplate was covered and allowed to stand for $2 \mathrm{~h}$ to allow for color development. Subsequently, we measured light absorption at $492 \mathrm{~nm}$ on a plate reader. The results are expressed as $\mathrm{mmol} / \mathrm{ml}$ urine. Samples were processed in two separate assays. The average intra-assay coefficient of variation for both assays was $10.2 \%$ and the inter-assay coefficient of variation was $17.0 \%$.

We determined the hormone concentrations using commercial radioimmunoassay kits (Coat-A-Count, Diagnostic 
Products, United States) that have been previously validated for the study species (Lutermann et al., 2012). The antiserum is highly specific for testosterone, with a cross reactivity for dihydrotestosterone being less than 5\%. A series of known calibrators of testosterone were assayed to set up a standard curve. Urine samples $(50 \mu \mathrm{l})$ and 125I-labeled testosterone $(1,000 \mu \mathrm{l})$ were added to assay tubes in duplicate and briefly vortexed. Assay tubes were incubated in a water bath $\left(37^{\circ} \mathrm{C}\right)$ for $3 \mathrm{~h}$. Bound and free 125I-labeled testosterone were decanted and the bound fraction on the tubes counted on a Cobra gamma counter for a minute. A calibration curve was used to convert the counts into testosterone concentrations. A serial double dilution of a sample containing a high concentration of testosterone paralleled the standard curve (ANCOVA: $F=2.8, P>0.05$ ) following log-logit transformation of the data (Chard, 1978). The sensitivity of the assay was $0.04 \mathrm{nmol} / \mathrm{l}$ and the intra-assay coefficient of variation was $7.5 \%$ and inter-assay coefficient of variation $12.1 \%$.

Cortisol was measured using a Coat-A-Count cortisol kit (Diagnostic Products Corporation, United States) using the same procedure as described above for the testosterone assay. A volume of $25 \mu \mathrm{l}$ of urine was used. The assay tubes were, however, incubated in the waterbath $\left(37^{\circ} \mathrm{C}\right)$ for $45 \mathrm{~min}$. A serial double dilution of the sample containing a high concentration of cortisol paralleled the standard curve (ANCOVA: $F=1.34, P>0.05$ ). The sensitivity of the assay was $4.82 \mathrm{nmol} / \mathrm{l}$. The average intra-assay coefficient of variation was $24.71 \%$ and the inter-assay coefficient of variation was $22.12 \%$.

\section{Statistical Analyses}

We tested for possible effects of cestode infestation on body condition (measured as body mass) and hormone levels and the time females were inactive with $t$-tests. Hormone data were $\log$-transformed prior to analyses to achieve a parametric distribution. Due to the large variance observed in values for both hormones we evaluated possible sample size limitations on the outcome of these tests by calculating effect sizes in and computing the post hoc power in G*Power 3.1.9 (Faul et al., $2007,2009)$. In order to determine whether any initial choice preferences existed for healthy and infested females we compared the first-choice chamber entered (i.e., healthy or infested male odor) using a $\chi^{2}$-test. These statistical analyses were carried out in IBM SPSS (version 25).

To evaluate the effect of female and male infestation on the frequency to enter a choice arm or a choice chamber we employed generalized linear mixed models (GLMMs) with a Poisson distribution and a log-link function. Female and male infestation status (healthy/infested) as well as the 2-way interaction between these variables were added as independent variables in the model. In addition, the concentration of testosterone and cortisol were added as covariates. Female ID as well as the ID of the male combination were included as random effects to control for repeated measurements. We converted the time spent in the choice chambers to proportions before analyzing the effects of female and male infestation status as well as male hormone levels on female preferences using a general linear mixed model.
These analyses were carried out with the statistical software $\mathrm{R}$ (version 3.6.1, R Core Team 2019) ${ }^{1}$ using the $\mathrm{R}$ package lme4 (Aguiar and Sala, 1998). The corresponding $p$-values were calculated with the R package car (Fox and Weisberg, 2011). ${ }^{2}$ We used the R package emmeans for post hoc multiple comparisons with Tukey's HSD (Lenth, 2019). ${ }^{3}$ We simplified models by sequentially dropping non-significant terms using the drop1 function in $\mathrm{R}$ to obtain the most parsimonious model based on the lowest AIC value (Burnham and Anderson, 2002). $P$-values of $\leq 0.05$ were considered to be significant and results are reported as mean \pm standard error (SE).

\section{RESULTS}

\section{Male Traits}

There was no significant difference between the body masses of healthy $(131.5 \pm 6.4 \mathrm{~g})$ and infested males $(118.1 \pm 8.5 \mathrm{~g}, n=30$, $t=1.25, \mathrm{df}=28 ; p=0.220)$. Furthermore, healthy $(139.8 \pm 21.5$ $\mathrm{nmol} / \mathrm{mmol}$ creatinine) and infested males (105.6 \pm 19.92 $\mathrm{nmol} / \mathrm{mmol}$ creatinine) did not differ significantly in their testosterone levels $(t=-1.22, \mathrm{df}=28 ; p=0.234)$. The effect size for this comparison were moderate (Cohen's $d=0.44$ ) and the power low at $\beta=0.282$. Although healthy males tended to have lower cortisol levels $(264.4 \pm 86.6 \mathrm{nmol} / \mathrm{mmol}$ creatinine) than infested males $(554.7 \pm 153.3 \mathrm{nmol} / \mathrm{mmol}$ creatinine) this was not significant $(t=-1.83, \mathrm{df}=28, p=0.078)$. The effect size for this comparison were fairly high (Cohen's $d=0.67)$ and the power moderate at $\beta=0.558$. There was no correlation between the testosterone and cortisol levels of males $\left(R_{S}=0.050, n=30, p=0.803\right)$. Differences in testosterone levels between healthy and infested male pairs varied widely (mean $\mathrm{T}_{\text {healthy }}-\mathrm{T}_{\text {infested }}$ : $-34.20 \pm 33.52 \mathrm{nmol} / \mathrm{mmol}$ creatinine, range: -235.96 to 345.73$)$. Similarly, the difference in cortisol level between healthy and infested males varied widely (mean $\mathrm{T}_{\text {infested }}-\mathrm{T}_{\text {healthy }}: 290.28 \pm 188.68 \mathrm{nmol} / \mathrm{mmol}$ creatinine, range: -922.21 to 1971.78 ).

\section{Parasite Effects on Females}

Body mass did not differ significantly between healthy $(98.7 \pm 3.5 \mathrm{~g})$ and infested females $(87.3 \pm 5.1 \mathrm{~g}, t=1.86$, $\mathrm{df}=28, p=0.074)$. Ten of the healthy females and eight of the infested females first entered the chamber with the odor from a healthy male. There was no significant difference in the initial choice to enter a chamber between healthy and infested females $\left(\chi^{2}=0.456, \mathrm{df}=1, p=0.710\right)$.

Female infestation status did not significantly affect the time spent inactive during the preference trials (healthy: $26.75 \% \pm 4.88$, infested: $41.34 \% \pm 7.11, t=-1.694, \mathrm{df}=28$, $p=0.101)$. However, the frequency to enter a choice arm was significantly larger for healthy $(15.1 \pm 1.0)$ compared to infested females $\left(6.0 \pm 0.7\right.$, Wald $\chi^{2}=41.7886, \mathrm{df}=1, p<0.0001$, Figure 1). Conversely, the infestation status of the male had no

\footnotetext{
${ }^{1}$ https://www.R-project.org/

${ }^{2}$ http://socserv.socsci.mcmaster.ca/jfox/Books/Companion

${ }^{3}$ https://CRAN.R-project.org/package $=$ emmeans
} 


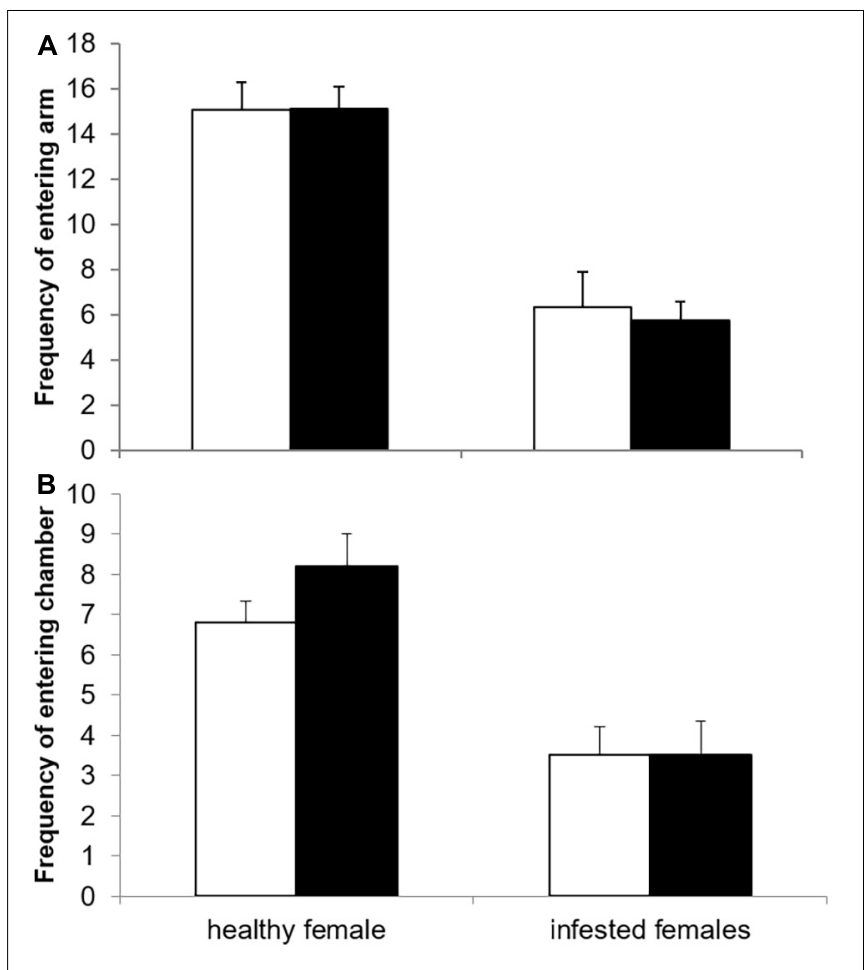

FIGURE 1 | Frequency of (A) entering the choice arm and (B) the choice chamber with the odor of a healthy (open bars) or infested male (solid bars) for healthy and infested female highveld mole-rats.

significant effect on the frequency of entering the choice arm and this variable was dropped from the final model. However, the frequency of entering the choice arm decreased slightly, but significantly, with increasing testosterone level (estimate: $0.0013 \pm 0.0006$, Wald $\chi^{2}=4.1224$, df $=1, p=0.042$ ). The remaining factors including the variable cortisol were all dropped from the final model (Table 1).

The infestation status of the female was the only variable retained in the final model for the frequency to enter the choice chamber (Table 1). It was significantly higher for healthy females (7.5 \pm 0.5$)$ compared to infested females (3.53 \pm 0.5 , Wald $\chi^{2}=19.391, \mathrm{df}=1, p<0.0001$, Figure 1).

Neither the female $\left[F_{(1,28)}=0.00, p=1.00\right]$, nor the male infestation status $\left.\left[F_{(1}, 27\right)=0.74, p=0.396\right]$ had a significant effect on the proportion of time a female spent with an odor sample. However, there was a significant interaction between female and male infestation status $\left[F_{(1,27)}=15.19, p=0.0006\right.$, Figure 2]. Healthy females spend significantly more time with the odor of the parasitized male than that of the healthy male $(t=2.94$, df $=28, p=0.032$, Figure 2$)$. In contrast, there was no significant difference in the proportion of time spent with an odor of healthy and infested males for infested females $(t=0.30$, $\mathrm{df}=28, p=0.990)$. As a result, healthy females spent significantly less time with a healthy male's odor compared to infested females $(t=2.75, \mathrm{df}=28, p=0.050)$ while the opposite was true for the odor of an infested male $(t=-2.75$, $\mathrm{df}=28, p=0.048)$. Furthermore, the time spent with a male odor was not affected significantly by the level of cortisol $\left[F_{(1,27)}=3.90, p=0.059\right]$. The variable testosterone was dropped from the final model (Table 1).

\section{DISCUSSION}

In accordance with our first prediction, female highveld molerats were able to distinguish between the urinary cues from healthy and infested males. However, contrary to several studies in laboratory mice and rats (Kavaliers and Colwell, 1995a,b; Penn et al., 1998; Willis and Poulin, 2000; Ehman and Scott, 2001) and in contrast to our second prediction healthy females spent more time inspecting odor cues from infested males. Although a lack of distinct preference of healthy rodent females has been reported in several studies (Klein et al., 1999; Gourbal and Gabrion, 2004; Ilmonen et al., 2009), clear preferences for infested male rodents have rarely been observed (Moshkin et al., 2002; Barthélémy et al., 2005; Dass et al., 2011). For mice infested with the protozoan Toxoplasma gondii, or the tick-borne encephalitis (TBE) virus such reversed preferences coincided with infection-related increases in male testosterone levels (Moshkin et al., 2002; Dass et al., 2011). Thus, they may be a result of parasite manipulation. Such manipulation would increase pathogen/parasite transmission to a sexual partner (T. gondii) or a vector (TBE virus) as a result of testosteronedriven increases in sexual behavior and roaming for mates (Lutermann, 2019). However, a similar mechanism is unlikely to apply in the study species as testosterone levels did not vary systematically with infestation status. In addition, testosteronedriven roaming behavior is severely restricted in the subterranean niche and such behavior would not assist the transmission of a parasite with an indirect life cycle such as Mathevotaenia.

It has been suggested that anthelminthic treatment with ivermectin may affect the host microbiome which could affect fecal odor (He et al., 2018). However, although several other studies report an effect of helminth parasites on microbiome communities, they could not find an effect of the drug on microbiome composition (Schneeberger et al., 2018; Peachey et al., 2019; Fujishiro et al., 2020; Hu et al., 2020). Hence, we are confident that our anthelminthic treatment did not unduly affect the urinary odor profiles of the males in our study. Similarly, ivermectin has been shown to affect the olfactory bulb in the brain of laboratory mice when injected (Obenhaus et al., 2016). However, this effect was only temporarily and no longer detectable after 7 days (Obenhaus et al., 2016). Consequently, our treatment is unlikely to have affected the ability of females to distinguish between healthy and infested males as the time period elapsed between treatment and choice experiments substantially exceeded 7 days. This hypothesis is further corroborated by the fact that healthy females (i.e., those treated with ivermectin) clearly distinguished between odors from healthy and infested males.

It has been shown in free-ranging species that infested males may be preferred by females as mates based on their body size (Cramer and Cameron, 2007; Chesh et al., 2012). This could be linked to higher testosterone levels in larger males irrespective of parasite infestation (Lopes and König, 2016). 
TABLE 1 | Final models for the effects of female and male infestation status and hormone levels on female C. $h$. pretoriae preferences.

\begin{tabular}{|c|c|c|c|c|c|c|c|c|c|}
\hline \multirow[b]{2}{*}{ Variable } & \multicolumn{3}{|c|}{ Frequency entering arm } & \multicolumn{3}{|c|}{ Frequency entering choice chamber } & \multicolumn{3}{|c|}{$\%$ time in choice chamber } \\
\hline & $\boldsymbol{F}$ & $d f$ & $p$ & $\boldsymbol{F}$ & $d f$ & $p$ & $\boldsymbol{F}$ & $d f$ & $p$ \\
\hline Female infestation status & 41.789 & 1 & $<0.0001$ & 19.391 & 1 & $<0.0001$ & 0.000 & 1 & 1.000 \\
\hline Male infestation status & - & - & - & - & - & - & 0.744 & 1 & 0.396 \\
\hline Female infestation status $\times$ male infestation status & - & - & - & - & - & - & 15.189 & 1 & $<0.0001$ \\
\hline Testosterone & 4.122 & 1 & 0.042 & - & - & - & - & - & - \\
\hline Cortisol & - & - & - & - & - & - & 3.898 & 1 & 0.059 \\
\hline
\end{tabular}

Significant variables are highlighted in bold.

However, in accordance with a previous study in highveld molerats (Lutermann et al., 2012), urinary hormone levels were not correlated with male body mass in our study making this an unlikely mechanism in the study species. This could be related to the social modulation of androgens in social bathyergids.

Ilmonen et al. (2009) showed that genetic variability may play a more important role than infestation status in mate preferences of mice. Consequently, the observed pattern could be an indicator of female preference for genetically different males based either on major histocompatibility complex (MHC) genes or general genetic variability (Penn and Potts, 1998; Ilmonen et al., 2009). The expression of MHC genes also affects the blend of peptides contained in murine urine. As gene expression is modulated by parasite infestation, infestation status can also affect urinary odors (Penn and Potts, 1998; Zala et al., 2004; Stowers and Tsuang-Han, 2015). This could have affected odor attraction of healthy females (Zala et al., 2004; Kumar et al., 2014; Moore et al., 2015). However, a systematic alignment between infestation status and genetic make-up in our sample of males appears to be unlikely. Furthermore, genetic data from the closely related common mole-rats (Cryptomys hottentotus hottentotus) suggest that females that choose sub-optimal males with regards to genetic variability seek to compensate for this by engaging in extra-pair matings with males from neighboring colonies (Bishop et al., 2007). Currently, there is no comparable information available for the study species. However, as the sub-terranean niche substantially increases the costs of breeding dispersal a similar scenario likely applies to highveld molerats.

Rather than choosing based on infestation status or male quality (e.g., hormone level, body size, genetic quality) it has been suggested for several vertebrate species where healthy females do not discriminate against infested males that females requiring male care may choose males to secure parental care (Klein et al., 1999; Mazzi, 2004). In monogamous California mice parental behavior has been linked to male testosterone levels (Gleason et al., 2012). Such information may be conveyed via olfactory cues (Kavaliers et al., 2005; Choleris et al., 2009) and could potentially account for the weak negative correlation between testosterone levels and female preferences observed in the current study.

None of the hypotheses presented above explain why we observed entirely different preferences in infested females that, contrary to our prediction, preferred healthy males. Although healthy and infested females did not differ in their time spent active, infested females exhibited a significantly lower degree of exploration as evidenced by their lower frequency of entering the choice arms and chambers. This could indicate that infested females do indeed experience constraints to their ability to choose (Poulin and Vickery, 1996; Jennions and Petrie, 1997; López, 1999; Beltran-Bech and Richard, 2014; Kavaliers and Choleris, 2018) while they are able to maintain a similar body mass as healthy females. However, unlike in many other studies this did not result in a lack of discrimination (Beltran-Bech and Richard, 2014), but a preference for healthy males. To the best of our knowledge there are no other examples of such strikingly opposing mate preferences between healthy and infested females in the literature. Since our study species is highly social, we propose that social cues experienced in the natal group may play a crucial role in the observed preferences. The role of social cues for mate choice decisions has previously been addressed in several laboratory studies and it has been shown that pre-exposure to males can modify olfactory preferences of both healthy and infested female mice depending on the infestation status of the odor donor (Kavaliers et al., 2003, 2006). The female highveld mole-rats tested in the current study probably only had limited exposure to potential mates due to the social system of the species and their subterranean lifestyle. However, as group-living species they may be exposed to the odor of related males which constitute undesirable mating partners. In addition, infestation status is frequently the same

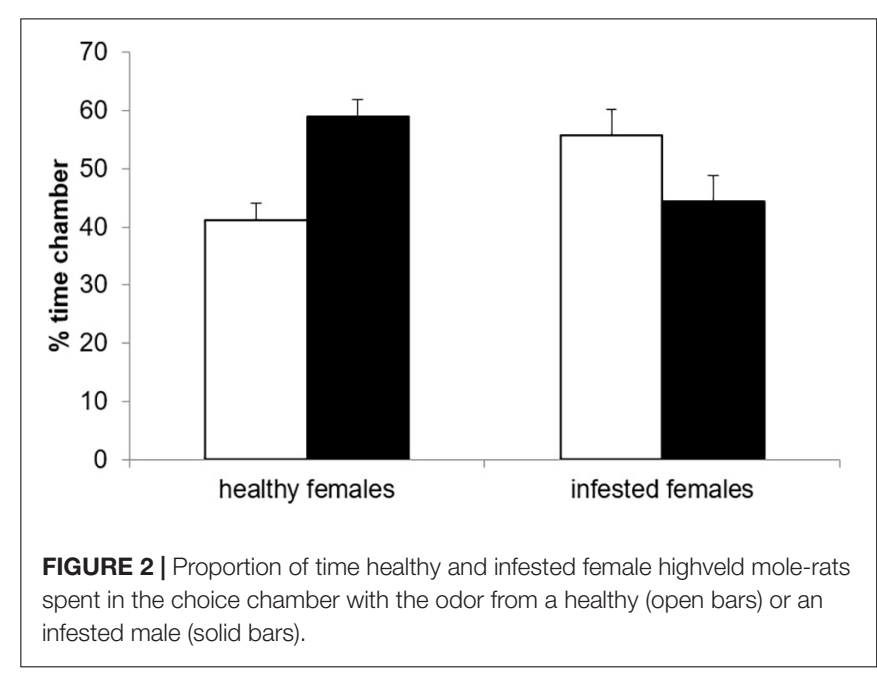


among colony members in the Bathyergidae including the study species (Viljoen et al., 2011; Lutermann et al., 2013; Archer et al., 2016). Furthermore, a recent study suggests that in rodents the olfactory profile of healthy individuals living with sick cage mates reflects the health status of the cage mates rather than that of the healthy individual (Gervasi et al., 2018). If similar adjustments of odor profiles are present in highveld mole-rats, the observed odor preferences of both healthy (i.e., living with healthy males) and infested females (i.e., living with infested males) may reflect a preference for unfamiliar male odors (i.e., infested for healthy females, healthy for infested females) rather than a preference or avoidance of odors of infested males. For long-lived species such as African mole-rats securing an unfamiliar and hence, likely unrelated mate that can enable successful breeding dispersal as well as provide parental care may take precedence over parasite avoidance, particularly for parasites that are not directly transmitted such as cestodes. This hypothesis awaits testing in this and other social species in the future. Furthermore, the social life-style of the study species allows for buffering of the costs incurred by parasites in molerats (Lutermann et al., 2013). However, odor preferences do not always translate into mate preferences (Clarke and Faulkes, 1999; Gourbal and Gabrion, 2004) and the indiscriminate matings observed in a number of mole-rats including the study species (Bennett et al., 1996, 1997, 2000; Clarke and Faulkes, 1999; Greeff and Bennett, 2000; Clarke et al., 2001; Bappert et al., 2012, Butler and Bennett, personal observation) suggest that although capable of discrimination mole-rats may choose to ignore the cues used to discriminate.

Contrary to our prediction, information about the infestation status is unlikely to be linked to the expression of androgens in the study species. This may be a result of the chronic nature of the natural cestode infestation which contrasts with the acute infestation used in many laboratory studies (Beltran-Bech and Richard, 2014). This is corroborated by a previous study of body mass and hormone levels in highveld mole-rats in response to chronic cestode infestation with testosterone, but not body mass or cortisol levels differing with infestation status while only the latter increased in response to a bacterial challenge (Lutermann et al., 2012). Nevertheless, it may also be a result of sample size limitations. Our power analysis suggests that due to the large variance in testosterone levels larger samples sizes $(n=78)$ would have been required to identify such differences. Similar limitations applied to a lesser extent for cortisol (required $n=29$ ) due to the greater effect size observed for this hormone. Regardless, the lack of apparent differences in hormone levels between the two groups of males should be treated with caution. The blend of pheromones and peptides contained in urine that are linked to the expression of major urinary proteins (MUPs) and MHC genes in murid rodents (Hurst, 2009; Stowers and Tsuang-Han, 2015) may be the basis for the observed discrimination. However, unlike in murid rodents MUPs concentrations are low in mole-rats (Hagemeyer et al., 2011).

Sensory deprivation in the subterranean environment renders visual and auditory cues less useful and suggests a significant role for olfactory signals in subterranean rodents (Francescoli, 2000). The strength of this selection pressure is illustrated for Bathyergidae by the high genetic variability at loci coding for olfactory receptors that has been reported for this family (Stathopoulos et al., 2014). At the same time, members of the three social genera, Heterocephalus, Fukomys, and Cryptomys, show little postnatal growth of the vomeronasal organ neuroepithelium, but also great within-species variability of the vomeronasal organ neuroepithelium (Dennis et al., 2020). While the current study is the first investigating the role of olfaction in a members of the genus Cryptomys, a number of studies in the other social genera have provided evidence for the ability of African mole-rats to discriminate between conspecifics based on olfactory cues (Heth and Todrank, 2007; Toor et al., 2015; Leedale et al., 2021). Although the basis of the observed discrimination in female highveld mole-rat remains to be investigated, the current study demonstrates the ability of a member of Cryptomys spp. to discriminate olfactory cues related the infestation status of conspecifics.

\section{CONCLUSION}

In conclusion, our study shows that irrespective of infestation status female highveld mole-rats are able to discriminate between healthy and infested male urinary odors. Contrary to other rodent species healthy females prefer the odors of infested males, whereas infested females prefer those of healthy males. In addition, infested females exhibited compromised activity levels. This choice is not based on infestation-related changes in male or females body mass, or male hormone levels. Instead, they may be related to social cues experienced in the natal group and this may also be relevant for other social vertebrate species.

\section{DATA AVAILABILITY STATEMENT}

The raw data supporting the conclusions of this article will be made available by the authors, without undue reservation.

\section{ETHICS STATEMENT}

The animal study was reviewed and approved by the Animal Ethics Committee of the University of Pretoria (EC 14-09) and capture permits were obtained from Gauteng Nature Conservation.

\section{AUTHOR CONTRIBUTIONS}

HL conceived and designed this study, performed the statistical analysis, and wrote the first draft of the manuscript. NB secured funding for the project. $\mathrm{KB}$ carried out the experiments. $\mathrm{KB}$ and $\mathrm{NB}$ conducted the hormone analyses. All authors contributed to manuscript revision and approved the submitted version. 


\section{FUNDING}

Funding for this project was provided by the DST-NRF South African Research Chair for Behavioural Ecology and Physiology to NB (GUN6475). HL also acknowledges funding from the University of Pretoria.

\section{REFERENCES}

Able, D. J. (1996). The contagion indicator hypothesis for parasite-mediated sexual selection. Proc. Natl. Acad. Sci. U S A 93, 2229-2233. doi: 10.1073/pnas.93.5. 2229

Aguiar, M. R., and Sala, O. E. (1998). Interactions among grasses, shrubs, and herbivores in Patagonian grass-shrub steppes. Ecol. Austral 8, 201-210. doi: 10.18637/jss.v067.i01

Aguilar, T. M., Maia, R., Santos, E. S. A., and Macedo, R. H. (2008). Parasite levels in blue-black grassquits correlate with male displays but not female mate preference. Behav. Ecol. 19, 292-301. doi: 10.1093/beheco/arm130

Andersson, M. (1994). Sexual Selection. (Princeton, NJ: Princeton University Press).

Archer, E. K., Bennett, N. C., Faulkes, C. G., and Lutermann, H. (2016). Digging for answers: contributions of frequency- and density-dependent mechanisms on ectoparasite burden in a social host. Oecologia 180, 429-438. doi: 10.1007/ s00442-015-3494-0

Bappert, M., Burda, H., and Begall, S. (2012). To mate or not to mate? mate preference and fidelity in monogamous ansell's mole-rats, Fukomys anselli, Bathyergidae. Folia Zool. 61, 71-83. doi: 10.25225/fozo.v61.i1.a11.2012

Barthélémy, M., Gabrion, C., and Petit, G. (2005). Does chronic malaria modify the odours of its male mouse host? Can. J. Zool. 83, 1079-1086. doi: 10.1139/Z05080

Beltran-Bech, S., and Richard, F.-J. (2014). Impact of infection on mate choice. Anim. Behav. 90, 159-170. doi: 10.1016/j.anbehav.2014.01.026

Bennett, N. C., and Faulkes, C. G. (2000). African Mole-Rats: Ecology and Eusociality. (Cambridge, UK: Cambridge University Press).

Bennett, N. C., Faulkes, C. G., and Molteno, A. J. (1996). Reproductive suppression in subordinate, non-breeding female Damaraland mole-rats: two components to a lifetime of socially induced infertility. Proc. R. Soc. B 263, 1599-1603. doi: 10.1098/rspb.1996.0234

Bennett, N. C., Faulkes, C. G., and Spinks, A. C. (1997). LH responses to single doses of exogenous GnRH by social Mashona mole-rats: a continuum of socially induced infertility in the family Bathyergidae. Proc. R. Soc. B 264, 1001-1006 doi: 10.1098/rspb.1997.0138

Bennett, N. C., Molteno, A. J., and Spinks, A. C. (2000). Pituitary sensitivity to exogenous GnRH in giant Zambian mole-rats, Cryptomys mechowi (Rodentia: Bathyergidae): support for the 'socially induced infertility continuum'. J. Zool. 252, 447-452.

Bishop, J. M., O’Ryan, C., and Jarvis, J. U. M. (2007). Social common mole-rats enhance outbreeding via extra-pair mating. Biol. Lett. 3, 176-179. doi: 10.1098/ rsbl.2006.0607

Bonney, R. C., Wood, D. J., and Kleiman, D. G. (1982). Endocrine correlates of behavioural oestrous in female giant panda (Ailuropoda melanoleuca) and associated hormonal changes in the male. J. Reprod. Fertil. 64, 209-215. doi: 10.1530/jrf.0.0640209

Buchholz, R. (2004). Effects of parasitic infection on mate sampling by female wild turkeys (Meleagris gallopavo): should infected females be more or less choosy? Behav. Ecol. 15, 687-694. doi: 10.1093/beheco/arh066

Burnham, K. P., and Anderson, D. R. (2002). Model Selection and Multimodel Inference, 2nd Edn. (New York, N Y: Springer Verlag).

Chard, T. (1978). An Introduction to Radioimmunoassay and Related Techniques, 3rd Edn. Amsterdam: Elsevier.

Chesh, A. S., Mabry, K. E., Keane, B., Noe, D. A., and Solomon, N. G. (2012). Are body mass and parasite load related to social partnerships and mating in Microtus ochrogaster? J. Mammal. 93, 229-238. doi: 10.1644/10-MAMM-A399.1

Choleris, E., Clipperton-Allen, A. E., Phan, A., and Kavaliers, M. (2009) Neuroendocrinology of social information processing in rats and mice. Front Neuroendocrinol. 30:442-459. doi: 10.1016/j.yfrne.2009.05.003

\section{ACKNOWLEDGMENTS}

We are indebted to the owners of various properties in Tshwane for access to their properties for animal capture and Hermien Viljoen for help with animal capture and maintenance.

Clarke, F. M., and Faulkes, C. G. (1999). Kin discrimination and female mate choice in the naked mole-rat Heterocephalus glaber. Proc. R. Soc. B 266, 1995-2002. doi: 10.1098/rspb.1999.0877

Clarke, F. M., Miethe, G. H., and Bennett, N. C. (2001). Reproductive suppression in female Damaraland mole-rats Cryptomys damarensis: dominant control or self-restraint? Proc. R. Soc. B 268, 1259-1263. doi: 10.1098/rspb.2000.1426

Cramer, M. J., and Cameron, G. N. (2007). Effects of bot fly, Cuterebra fontinella, parasitism on male aggression and female choice in Peromyscus leucopus. Anim. Behav. 74, 1419-1427. doi: 10.1016/j.anbehav.2007.02.010

Dass, S. A. H., Vasudevan, A., Dutta, D., Soh, L. J. T., Sapolsky, R. M., and Vyas, A (2011). Protozoan parasite Toxoplasma gondii manipulates mate choice in rats by enhancing attractiveness of males. PLoS One 6:e27229. doi: 10.1371/journal. pone. 0027229

Dennis, J. C., Stilwell, N. K., Smith, T. D., Park, T. J., Bhatnagar, K. P., and Morrison, E. E. (2020). Is the mole rat vomeronasal organ functional? Anat. Rec. 303, 318-329. doi: 10.1002/ar.24060

Ehman, K. D., and Scott, E. (2001). Urinary odour preferences of MHC congenic female mice, Mus domesticus: implications for kin recognition and detection of parasitized males. Anim. Behav. 62, 781-789. doi: 10.1006/anbe.2001.1805

Faul, F., Erdfelder, E., Buchner, A., and Lang, A.-G. (2009). Statistical power analyses using $\mathrm{G}^{*}$ Power 3.1: tests for correlation and regression analyses. Behav. Res. Methods 41, 1149-1160. doi: 10.3758/BRM.41.4.1149

Faul, F., Erdfelder, E., Lang, A.-G., and Buchner, A. (2007). G*Power 3: a flexible statistical power analysis program for the social, behavioral, and biomedical sciences. Behav. Res. Methods 39, 175-191. doi: 10.3758/bf03193146

Ferkin, M. H. (2018). Odor communication and mate choice in rodents. Biology. 7:13. doi: 10.3390/biology7010013

Folstad, I., and Karter, A. J. (1992). Parasites, bright males, and the immunocompetence handicap. Am. Nat. 139, 603-622. doi: 10.1016/j.ygcen. 2021.113717

Fox, J., and Weisberg, S. (2011). An $\{R\}$ Companion to Applied Regression, 2nd Edn. (Thousand Oaks CA: Sage)

Francescoli, G. (2000). "Sensory capabilities and communication in subterranean mammals," in Life Underground: the Biology of Subterranean Rodents, eds E. A. Lacey, J. L. Patton, and G. N. Cameron (Chicago: University of Chicago Press). 111-144.

Fujishiro, M. A., Lidbury, J. A., Pilla, R., Steiner, J. M., Lappin, M. R., and Suchodolski, J. S. (2020). Evaluation of the effects of anthelmintic administration on the fecal microbiome of healthy dogs with and without subclinical Giardia spp. and Cryptosporidium canis infections. PLoS One 15:e0228145. doi: 10.1371/journal.pone.0228145

Gervasi, S. S., Opiekun, M., Martin, T., Beauchamp, G. K., and Kimball, B. A. (2018). Sharing an environment with sick conspecifics alters odors of healthy animals. Sci. Rep. 8:14255. doi: 10.1038/s41598-018-32619-4

Gleason, E. D., Holschbach, M. A., and Marler, C. A. (2012). Compatibility drives female preference and reproductive success in the monogamous California mouse (Peromyscus californicus) more strongly than male testosterone measures. Horm. Behav. 61, 100-107. doi: 10.1016/j.yhbeh.2011.10.009

Gourbal, B. E. F., and Gabrion, C. (2004). A study of mate choice in mice with experimental Taenia crassiceps cysticercosis: can males choose? Can. J. Zool. 82, 635-643. doi: 10.1139/z04-038

Greeff, J. M., and Bennett, N. C. (2000). Causes and consequences of incest avoidance in the cooperatively breeding mole-rat, Cryptomys darlingi (Bathyergidae). Ecol. Lett. 3, 318-328. doi: 10.1046/j.1461-0248.2000.00162.x

Hagemeyer, P., Begall, S., Janotova, K., Todrank, J., Heth, G., Jedelsky, P. L., et al. (2011). Searching for major urinary proteins (MUPs) as chemosignals in urine of subterranean rodents. J. Chem. Ecol. 37, 687-694. doi: 10.1007/s10886-0119971-y

Hamilton, W. D., and Zuk, M. (1982). Heritable true fitness and bright birds: a role for parasites? Science 218, 384-387. doi: 10.1126/science.7123238 
Hazell, R. W. A., Bennett, N. C., Jarvis, J. U. M., and Grif, M. (2000). Adult dispersal in the co-operatively breeding Damaraland mole-rat (Cryptomys damarensis): a case study from the Waterberg region of Namibia. J. Zool. 252, 19-25. doi: 10.1111/j.1469-7998.2000.tb00816.x

He, F., Zhai, J., Zhang, L., Liu, D., Ma, Y., Rong, K., et al. (2018). Variations in gut microbiota and fecal metabolic phenotype associated with Fenbendazole and Ivermectin tablets by $16 \mathrm{~S}$ rRNA gene sequencing and LC/MS-based metabolomics in amur tiger. Biochem. Biophys. Res. Commun. 499, 447-453. doi: 10.1016/j.bbrc.2018.03.158

Heth, G., and Todrank, J. (2007). "Using odours underground," in Subterranean Rodents: News From the Underground, eds S. Begall, H. Burda, and C. E. Schleich (Berlin: Springer Verlag), 85-96.

Hickman, G. C. (1979). A live trap and trapping technique for fossorial mammals. South African J. Zool. 14, 9-12.

Hu, X., Xu, Y., Liu, G., Hu, D., Wang, Y., Zhang, W., et al. (2020). The impact of anthelmintic treatment on gut bacterial and fungal communities in diagnosed parasite-free sika deer Cervus nippon. Appl. Microbiol. Biotechnol. 104, 92399250. doi: 10.1007/s00253-020-10838-y

Hurst, J. L. (2009). Female recognition and assessment of males through scent. Behav. Brain Res. 22, 295-303. doi: 10.1016/j.bbr.2008.12.020

Ilmonen, P., Stundner, G., Thoß, M., and Penn, D. J. (2009). Females prefer the scent of outbred males: good-genes-as-heterozygosity? BMC Evol. Biol. 10:104. doi: 10.1186/1471-2148-9-104

Jarvis, J. U. M., O’Riain, M. J., Bennett, N. C., and Sherman, P. W. (1994). Mammalian eusociality: a family affair. Trends Ecol. Evol. 9, 47-51. doi: 10.1016/ 0169-5347(94)90267-4

Jennions, M. D., and Petrie, M. (1997). Variation in mate choice and mating preferences: a review of causes and consequences. Biol. Rev. Camb. Philos. Soc. 72, 283-327. doi: 10.1017/s0006323196005014

Johnston, R. E. (2003). Chemical communication in rodents: from pheromones to individual recognition. J. Mammal. 84, 1141-1162. doi: 10.1644/ble-010

Kavaliers, M., and Choleris, E. (2018). The role of social cognition in parasite and pathogen avoidance. Philos. Trans. R. Soc. B 373:20170206. doi: 10.1098/rstb. 2017.0206

Kavaliers, M., Choleris, E., Agmo, A., Braun, W. J., Colwell, D. D., Muglia, L. J., et al. (2006). Inadvertent social information and the avoidance of parasitized male mice: a role for oxytocin. Proc. Natl. Acad. Sci. U. S. A. 103, 4293-4298. doi: 10.1073/pnas.0600410103

Kavaliers, M., Choleris, E., and Pfaff, D. W. (2005). Genes, odours and the recognition of parasitized individuals by rodents. Trends Parasitol. 21, 423-429. doi: $10.1016 /$ j.pt.2005.07.008

Kavaliers, M., and Colwell, D. D. (1995a). Discrimination by female mice between the odours of parasitized and non-parasitized males. Proc. R. Soc. B 261, 31-35. doi: $10.1098 /$ rspb.1995.0113

Kavaliers, M., and Colwell, D. D. (1995b). Odours of parasitized males induce aversive responses in female mice. Anim. Behav. 50, 1161-1169. doi: 10.1016/ 0003-3472(95)80032-8

Kavaliers, M., Colwell, D. D., Braun, W. J., and Choleris, E. (2003). Brief exposure to the odour of a parasitized male alters the subsequent mate odour responses of female mice. Anim. Behav. 65, 59-68. doi: 10.1006/anbe.2002. 2043

Klein, S. L. (2003). Parasite manipulation of the proximate mechanisms that mediate social behavior in vertebrates. Physiol. Behav. 79, 441-449. doi: 10.1016/ S0031-9384(03)00163-X

Klein, S. L., Ray, H., and Nelson, R. J. (1999). Trichinella spiralis infection in voles alters female odor preference but not partner preference. Behav. Ecol. Sociobiol. 45, 323-329. doi: 10.1007/s002650050567

Kokko, H., Brooks, R., Jennions, M. D., and Morley, J. (2003). The evolution of mate choice and mating biases. Proc. R. Soc. B 270, 653-664. doi: 10.1098/rspb. 2002.2235

Kumar, V., Vasudevan, A., Soh, L. J. T., Le Min, C., Vyas, A., Zewail-Foote, M., et al. (2014). Sexual attractiveness in male rats is associated with greater concentration of major urinary proteins. Biol. Reprod. 91:150. doi: 10.1095/ biolreprod.114.117903

Lai, Te, Kekäläinen, J., and Kortet, R. (2016). Infestation with the parasitic nematode Philometra ovata does not impair behavioral sexual competitiveness or odor attractiveness of the male European minnow (Phoxinus). Acta Ethol. 19, 103-111. doi: 10.1007/s10211-015-0229-5
Leedale, A. E., Thorley, J., and Clutton-Brock, T. (2021). Odour-based social recognition in Damaraland mole-rats, Fukomys damarensis. Anim. Behav. 179, 83-96. doi: 10.1016/j.anbehav.2021.06.019

Lenth, R. (2019). emmeans: Estimated Marginal Means, Aka Least-Squares Means.

Litvinova, E., Kudaeva, O., Mershieva, L., and Moshkin, M. (2005). High level of circulating testosterone abolishes decline in scent attractiveness in antigentreated male mice. Anim. Behav. 69, 511-517. doi: 10.1016/j.anbehav.2004.05. 014

Lopes, P. C., and König, B. (2016). Choosing a healthy mate: sexually attractive traits as reliable indicators of current disease status in house mice. Anim. Behav. 111, 119-126. doi: 10.1016/j.anbehav.2015. 10.011

López, S. (1999). Parasitized female guppies do not prefer showy males. Anim. Behav. 57, 1129-1134. doi: 10.1006/anbe.199 8.1064

Lutermann, H. (2019). “Sex-biased parasitism," in Encyclopedia of Animal Behavior, (Amsterdam: Elsevier Science \& Technology), doi: 10.1016/b978-0-12-8096338.90725-8

Lutermann, H., Bennett, N. C., Speakman, J. R., and Scantlebury, M. (2013). Energetic benefits of sociality offset the costs of parasitism in a cooperative mammal. PLoS One 8:e57969. doi: 10.1371/journal.pone.00 57969

Lutermann, H., Bodenstein, C., and Bennett, N. C. (2012). Natural parasite infection affects the tolerance but not the response to a simulated secondary parasite infection. PLoS One 7:e52077. doi: 10.1371/journal.pone.00 52077

Malherbe, G. P., Schoeman, A. S., and Bennett, N. C. (2004). Is the highveld mole-rat Cryptomys hottentotus pretoriae (Rodentia: Bathyergidae) an induced or spontaneous ovulator? J. Zool. 263, 159-165. doi: 10.1017/S0952836904 004996

Mazzi, D. (2004). Parasites make male pipefish careless. J. Evol. Biol. 17, 519-527. doi: 10.1111/j.1420-9101.2004.00704.x

Milinski, M., and Bakker, T. C. M. (1992). Costs influence sequential mate choice in sticklebacks, Gasterosteus aculeatus. Proc. R. Soc. B 250, 229-233. doi: 10.1098/ rspb.1992.0153

Moore, F. R., Shuker, D. M., and Dougherty, L. (2015). Stress and sexual signaling: a systematic review and meta-analysis. Behav. Ecol. 27, 363-371. doi: 10.1093/ beheco/arv195

Moshkin, M., Gerlinskaya, L., Morozova, O., Bakhvalova, V., and Evsikov, V. (2002). Behaviour, chemosignals and endocrine functions in male mice infected with tick-borne encephalitis virus. Psychoneuroendocrinology 27, 603-608. doi: 10.1016/S0306-4530(01)00096-8

Obenhaus, H. A., Rozov, A., Bertocchi, I., Tang, W., Kirsch, J., Betz, H., et al. (2016). Causal interrogation of neuronal networks and behavior through virally transduced ivermectin receptors. Front. Mol. Neurosci. 9:75. doi: 10.3389/fnmol. 2016.00075

Peachey, L. E., Castro, C., Molena, R. A., Jenkins, T. P., Griffin, J. L., and Cantacessi, C. (2019). Dysbiosis associated with acute helminth infections in herbivorous youngstock - observations and implications. Sci. Rep. 9:11121. doi: 10.1038/ s41598-019-47204-6

Penn, D., and Potts, W. K. (1998). Chemical signals and parasite-mediated sexual selection. Trends Ecol. Evol. 13, 391-396. doi: 10.1016/S0169-5347(98)0 1473-6

Penn, D., Schneider, G., White, K., Slev, P., and Potts, W. (1998). Influenza infection neutralizes the attractiveness of male odour to female mice (Mus musculus). Ethology 104, 685-694. doi: 10.1111/j.1439-0310.1998.tb00 102.x

Pfennig, K. S., and Tinsley, R. C. (2002). Different mate preferences by parasitized and unparasitized females potentially reduces sexual selection. J. Evol. Biol. 15, 399-406. doi: 10.1046/j.1420-9101.2002.00406.x

Poulin, R. (1994). Mate choice decisions by parasitized female upland bullies, Gobiomorphus breviceps. Proc. R. Soc. B Biol. Sci. 256, 183-187. doi: 10.1098/ rspb.1994.0068

Poulin, R. (2007). Evolutionary ecology of parasites. Princeton, NJ: Princeton University Press.

Poulin, R., and Vickery, W. L. (1996). Parasite-mediated sexual selection: just how choosy are parasitized females? Behav. Ecol. Sociobiol. 38, 43-49. doi: 10.1007/ s002650050215 
Schneeberger, P. H. H., Coulibaly, J. T., Gueuning, M., Moser, W., Coburn, B., Frey, J. E., et al. (2018). Off-target effects of tribendimidine, tribendimidine plus ivermectin, tribendimidine plus oxantel-pamoate, and albendazole plus oxantel-pamoate on the human gut microbiota. Int. J. Parasitol. Drugs Drug Resist. 8, 372-378. doi: 10.1016/j.ijpddr.2018. 07.001

Stathopoulos, S., Bishop, J. M., and O’Ryan, C. (2014). Genetic signatures for enhanced olfaction in the African mole-rats. PLoS One 9:e93336. doi: 10.1371/ journal.pone.0093336

Stowers, L., and Tsuang-Han, K. (2015). Mammalian pheromones: emerging properties and mechanisms of detection. Curr. Opin. Neurobiol. 34, 103-109. doi: 10.1016/j.conb.2015.02.005

Toor, I., Clement, D., Carlson, E. N., and Holmes, M. M. (2015). Olfaction and social cognition in eusocial naked mole-rats, Heterocephalus glaber. Anim. Behav. 107, 175-181. doi: 10.1016/j.anbehav.2015.06.015

van Rensburg, L., Bennett, N. C., van der Merwe, M., Schoeman, A. S., and Brinders, J. (2003). Are reproductive male highveld mole-rats, Cryptomys hottentotus pretoriae physiologically suppressed while in the confines of the natal colony? J. Zool. 260, 73-78. doi: 10.1017/S09528369030 03443

Viljoen, H., Bennett, N. C., Ueckermann, E. A., and Lutermann, H. (2011). The role of host traits, season and group size on parasite burdens in a cooperative mammal. PLoS One 6:e27003. doi: 10.1371/journal.pone. 0027003
Willis, C., and Poulin, R. (2000). Preference of female rats for the odours of nonparasitised males: the smell of good genes? Folia Parasitol. (Praha) 47, 6-10. doi: $10.14411 / \mathrm{fp} .2000 .002$

Zala, S. M., Potts, W. K., Penn, D. J., and Lake, S. (2004). Scent-marking displays provide honest signals of health and infection. Behav. Ecol. 15, 338-344. doi: 10.1093/beheco/arh022

Conflict of Interest: The authors declare that the research was conducted in the absence of any commercial or financial relationships that could be construed as a potential conflict of interest.

Publisher's Note: All claims expressed in this article are solely those of the authors and do not necessarily represent those of their affiliated organizations, or those of the publisher, the editors and the reviewers. Any product that may be evaluated in this article, or claim that may be made by its manufacturer, is not guaranteed or endorsed by the publisher.

Copyright (C) 2022 Lutermann, Butler and Bennett. This is an open-access article distributed under the terms of the Creative Commons Attribution License (CC BY). The use, distribution or reproduction in other forums is permitted, provided the original author(s) and the copyright owner(s) are credited and that the original publication in this journal is cited, in accordance with accepted academic practice. No use, distribution or reproduction is permitted which does not comply with these terms. 